
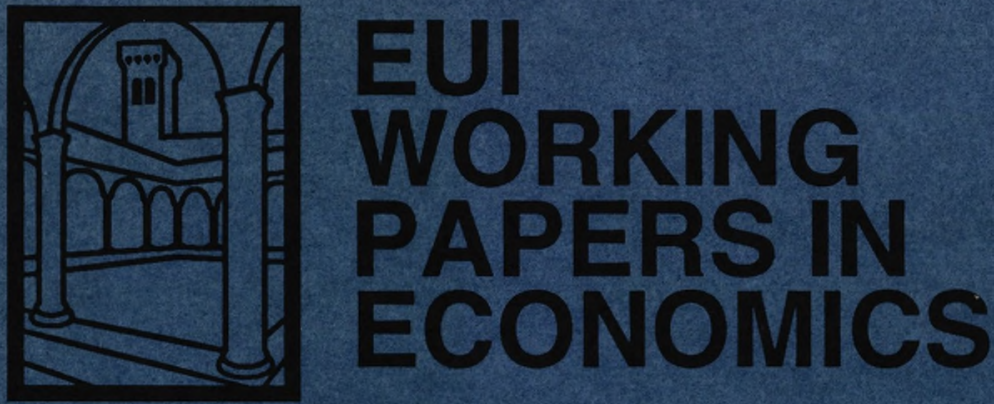

Alternative Time Patterns of Decisions and Dynamic Strategic Interactions

Pierre Cahuc and

HUBERT KEMPF की \&: 尺ें

(2) 
EUROPEAN UNIVERSITY INSTITUTE

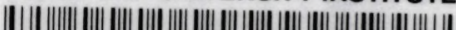


EUROPEAN UNIVERSITY INSTITUTE, FLORENCE

ECONOMICS DEPARTMENT

EUI Working Paper ECO No. 95/11

Alternative Time Patterns of Decisions

and Dynamic Strategic Interactions

PIERRE CAHUC

and

HUBERT KEMPF

WP 330

EUR

BADIA FIESOLANA, SAN DOMENICO (FI) 
All rights reserved.

No part of this paper may be reproduced in any form without permission of the authors.

(C) Pierre Cahuc and Hubert Kempf

Printed in Italy in May 1995

European University Institute

Badia Fiesolana

I - 50016 San Domenico (FI)

Italy 


\title{
ALTERNATIVE TIME PATTERNS OF DECISIONS AND DYNAMIC STRATEGIC INTERACTIONS
}

\author{
Pierre Cahuc - Hubert Kempf
}

Université Paris - 1 Panthéon - Sorbonne

\section{ABSTRACT}

This paper offers a simple approach to study steady-state Markov Perfect Equilibria arising in dynamic games when players (are obliged to) commit their actions to several periods : it highlights the importance of spillovers and dynamic strategic interactions when assessing the various time patterns conceivable in such games. The obtained results are then applied to various, either micro- or macroeconomic, issues where time patterns of decisions matter. 


\section{$\underline{\text { I-Introduction }}$}

In this paper we offer simple rules to assess time patterns of decisions in dynamic games, when players play Markov strategies, and we show how these rules can easily be applied to a wide variety of issues, from space exploration to trade wars in aircraft industries and to international monetary games.

The issue of the time pattern of decisions has been recurrent in macroeconomics since the now classic papers by Fisher (1977) and Taylor (1980), which claimed that, due to the staggering of multiperiodic wage contracts, feedback money supply is not neutral. But even though this assumption has proven very useful for modelling nominal rigidities and addressing many questions, it suffered from a lack of proper microeconomic foundations.

More recently, Maskin and Tirole in a series of papers (1988a, 1988b, 1987) addressed the same topic from a totally different point of view. Their perspective was microeconomic and more precisely, rooted in duopoly theory. Their objective in this series of papers was to explain how oligopolistic firms behave over time, assuming that each firm is committed to a particular action in the short run. In other words, as in Taylor (1980), one agent (here a firm in a duopoly) decides an action valid for several periods and cannot alter her decision during that span of time. In the case of non-synchronised decisions by the firms, the game becomes an infinite-horizon sequential game : a firm when it makes its decision has to take into account the delayed reaction of its competitor, then its own future answer to this answer and so, recurrently until infinity. In order to study the outcome of this type of game, Maskin and Tirole restricted their attention to Markov strategies and then studied the perfect equilibria corresponding to these strategies, which they called Perfect Markov Strategies (MPE) 1 .

One player is said to have a Markov strategy at time $t$ when she only takes into account actions by other players affecting her instantaneous payoff. As Maskin and Tirole (1988a) point out, the most obvious appeal of Markov strategies is their simplicity. In particular, even though they are without doubt ad hoc, they seem to accord better with the customary conception of what is a reaction in a relationship than the notion of reaction-through-threats developed in the repeated game tradition. Moreover, this last theory suffers from a multiplicity of solutions, and the use of Markov strategies appears as a nice way to overcome this difficulty, since it can be shown that they lead, under some conditions, to a unique perfect equilibrium.

\footnotetext{
${ }^{1}$ For a general presentation of MPEs, see Fudenberg-Tirole (1992), P. 513-520.
} 
But even though this concept is trully remarkable, its use in economic problems has proved to be rather awkward, because of the complexity of the necessary algebra. Furthermore, no systematic comparison between several MPE corresponding to several alternative time patterns of a given game with commitment, has been offered yet.

The aim of this paper is then twofold.

Firstly, we want to show that, in restricting attention to steady-states, MPE can easily be studied and characterised, without having to explicitly compute the solution of the game. The setting we consider is similar to the Maskin-Tirole setting. We consider games with two identical players, taking place in discrete time with an infinite horizon. Each player commits her action to two periods. Therefore, two time patterns emerge for such a game : the game may be synchronised (both players playing in the same period every two periods), or staggered (one player playing in odd periods, the other in even periods). Given this set of assumptions, considering a given unspecified game (that is, a game relying on an unspecified payoff function), we are able to compare the actions taken in both patterns and their relative efficiency. Strikingly, these comparisons will be shown to depend on characteristics of the instantaneous payoff function. Two features are crucial :

i - the nature of spillover effects between both players;

ii - the nature of strategic interactions (that is, strategic substitutability versus strategic complementarity) between both players.

Remarkably, these two features are those already highlighted by Cooper and John in their study of static, non-cooperative games. In this perspective, our analysis appears as the extension to dynamic games of their own analysis of static games. With two major differences. Firstly, whereas Cooper and John were mostly interested in multiple equilibria arising in static games (what they called "coordination failures"), we restrict our attention to cases where there exists a unique MPE. Secondly, contrarily to Cooper and John who consider games with an indeterminate number of agents, we focus on games with a small number of agents, that is, on games where each agent has a non-negligible weight on the outcome of the game.

Building upon these results, we then address the issue of endogenizing timing, already studied by Maskin and Tirole, and obtain a simple result : players will always choose to alternate decisions (stagger) when there exists strategic complementarity. The link between strategic complementarity and time pattern was recently studied by Cooper and Haltiwanger $(1992,1993)$ in specific models, 
who reached the opposite conclusion. This makes it clear that it is of crucial importance to be very precise about the type of game that is played and the nature of dynamic links between players.

Secondly, we want to use these general results to study various (highly stylized!) economic scenarios with spillovers and strategic interactions and show how they very easily allow us to understand the dynamic behaviour of players in these settings.

The plan of this paper, therefore, is as follows. Section II is devoted to the analysis of the conceivable time patterns in games with two-periods commitments and presents our theoretical propositions. We then offer in Section III several examples allowing us to apply these propositions. These examples are either micro- or macro-oriented. Henceforth, it should be clear that the potential of MPE as an economic tool is not confined to microeconomics but is also relevant for macroeconomics. We summarise our results and suggest possible extensions in section IV.

\section{II - Perfect Markov equilibria and dynamic strategic interactions}

We consider a game with two identical players. Each player i $(i=1,2)$ chooses actions $a^{t}$ from a bounded action space A. Players act in discrete time, and the horizon is infinite. Periods are indexed by $\mathrm{t}(\mathrm{t}=0,1, \ldots)$. At time $\mathrm{t}$, player i's instantaneous payoff $v^{i}$ is a function of the current actions of the two players :

$$
v_{t}^{i}=v\left(a_{t}^{i}, a_{t}^{-i}\right)
$$

$v($.$) is a quadratic and concave function.$

Players discount time with the same discount factor $\delta \in] 0,1$. Player i's intertemporal payoff can then be written :

$$
\vartheta_{t}^{i}=\sum_{\tau=0}^{\infty} \delta^{\tau} v\left(a_{t+\tau}^{i}, a_{t+\tau}^{-i}\right)
$$

We make two assumptions about strategies :

1 - The two players are committed to their actions for two periods. Henceforth, two types of time patterns emerge : players can act either simultaneously or sequentially. If they act simultaneously, the game is "synchronised"; if they act sequentially, the game is "staggered". 
2 - The strategy of a given player ( 1 or 2 ) is very simple : she only reacts to the current action of the other player. Hence, following Maskin and Tirole (1988a), we shall look for the subgame perfect equilibria whose strategies depend only on the "payoff relevant" history. More precisely, this means that strategies of player $i$ can specify an action at time $t$ only as a function of the actions of player $\mathrm{j}$ that are arguments of her instantaneous payoff function at date t. Such strategies are called "Markov strategies". They have the advantage to limit the strategy space of the players, and allow us to eliminate complicated strategies that would yield too many equilibria in a dynamic setting. A pair of "Markov strategies" that is subgame perfect is called a "Markov perfect equilibrium".

The aim of this section is then to compare the two stationary equilibria of the two patterns of the game, given these two assumptions.

\section{a) The synchronised game}

If the two players act simultaneously, the optimal Markov strategy of player $i$ is defined by the following program :

$$
\underset{a^{i}}{\operatorname{Mox}} \quad v\left(a^{i}, a^{-i}\right)+\delta v\left(a^{i}, a^{-i}\right)
$$

The first order condition implies :

$$
v_{1}\left(a^{i}, a^{-i}\right)=0
$$

where $v_{j}\left(a^{i}, a^{-i}\right)$ is the partial derivative with respect to the $\mathrm{j}$-th argument, $\mathrm{j}=1,2$, and the second-order condition is :

$$
v_{11}<0
$$

Equation (2) implicitly defines the reaction function $a^{i}=a\left(a^{-i}\right)$ of player i. We shall restrict our analysis to globally stable Markov perfect equilibria such that $\left|a^{\prime}().\right|<1$.

The implicit function theorem implies that :

$$
a^{\prime}\left(a^{-i}\right)=-\frac{v_{12}}{v_{11}}
$$

Therefore, the stability condition yields the following restriction on the payoff function : 


$$
\left|v_{11}\right|>\left|v_{12}\right|
$$

If eqs.(2) and (4) are fulfilled, there exists a unique symmetric equilibrium such that :

$$
a^{i}=a\left(a^{-i}\right)=\bar{a}, i=1,2
$$

and :

$$
v_{1}(\bar{a}, \bar{a})=0
$$

We immediately notice, from eq.(5) that the synchronised game yields the same outcome as the static game.

It is illuminating at this stage to introduce the following definitions, borrowed from Cooper-John (1988):

(i) if $v_{2}\left(a_{t}^{i}, a_{t}^{-i}\right)>0$, the game exhibits positive spillovers;

(ii) if $v_{2}\left(a_{t}^{i}, a_{t}^{-i}\right)<0$, the game exhibits negative spillovers;

(iii) if $v_{12}>0$, the game exhibits strategic complementarity;

(iv) if $v_{12}<0$, the game exhibits strategic substitutability.

Definitions (i) and (ii) are straightforward. According to (iii), there is "strategic complementarity" when an increase in the action of $-i$ increases the marginal return of i's action, and reinforces the effect of i's action. (iv) has the opposite meaning.

\section{b) The staggered game}

In the staggered game, let's say that Player 1 acts in odd periods $(t=1,3,5, \ldots)$ and Player 2 acts in even periods $(t=0,2,4, \ldots)$. According to Maskin and Tirole (1988a), we define two value functions for each player. Given a pair of Markov strategies $\left(R^{1}\left(a^{2}\right), R^{2}\left(a^{1}\right)\right)$, let $V^{i}\left(a^{-i}\right), i=1,2$, be the present discounted payoff to player $i$ given that last period player $-i$ played $a^{-i}$ and that henceforth both players act optimally, according to their Markov strategies, and let $W^{i}\left(a^{i}\right)$ be the present discounted payoff to player $i$, given that last period player $i$ played $a^{i}$ and that henceforth both players play optimally, according to their Markov strategies. 
$\left(R^{1}\left(a^{2}\right), R^{2}\left(a^{1}\right)\right)$ is a Markov Perfect Equilibrium if and only if there exist value functions $\left\{\left(V^{1}, W^{1}\right),\left(V^{2}, W^{2}\right)\right\}$ such that for any actions $\left(a^{1}, a^{2}\right) \in A^{2}$ :

$$
\begin{aligned}
& V^{i}\left(a^{-i}\right)=\underset{a^{d}}{\operatorname{Max}}\left\{v\left(a^{i}, a^{-i}\right)+\delta W^{i}\left(a^{i}\right)\right\} \\
& R^{i}\left(a^{-i}\right) \in \underset{a^{\prime}}{\arg } \operatorname{Max}\left\{v\left(a^{i}, a^{-i}\right)+\delta W^{i}\left(a^{i}\right)\right\} \\
& W^{i}\left(a^{i}\right)=v\left(a^{i}, R^{-i}\left(a^{i}\right)\right)+\delta V^{i}\left(R^{-i}\left(a^{i}\right)\right)
\end{aligned}
$$

We are looking for linear solutions, i.e. for linear dynamic reaction functions $R^{i}: a^{-i} \mapsto \alpha^{i}+\beta^{i} a^{-i}, \quad \alpha^{i} \in \Re$. Moreover, we shall focus on stable Markov Perfect Equilibria, such that $\left.\beta^{i} \in\right]-1,1\left[\right.$. From eq.(7), $R^{i}\left(a^{-i}\right)$ is defined by the following first-order condition :

$$
v_{1}\left(R^{i}\left(a^{-i}\right), a^{-i}\right)+\delta W^{\prime}\left(R^{i}\left(a^{-i}\right)\right)=0
$$

and the second-order condition :

$$
v_{11}+\delta W^{\prime \prime}\left(R^{i}\left(a^{-i}\right)\right)<0
$$

Before comparing outcomes of the staggered and synchronised games, we shall first state the following lemma giving conditions for existence and unicity for a stable MPE.

\section{Lemma :}

There exists a unique stable Markov Perfect Equilibrium to the game defined by eqs (6)-(8) if and only if the polynomial $P(\beta)$

$$
P(\beta) \equiv \beta^{4} \delta^{2} v_{12}+\beta^{3} \delta(1+\delta) v_{22}+2 \beta^{2} \delta v_{12}+\beta(1+\delta) v_{11}+v_{12}
$$

has only one real root in the interval $]-1,1\left[\right.$ and $\left|v_{11}\right|>\left|\delta v_{22}\right|$.

Proof: see Appendix 1. 
We shall assume, henceforth, that the condition defined in the previous lemma is fulfilled. Then we are able to state the following proposition :

\section{Proposition 1:}

The action taken in the staggered game $\hat{a}$ is bigger than the action taken in the synchronised game $\bar{a}$ if the game exhibits positive spillovers for $a=\bar{a}\left(v_{2}(\bar{a}, \bar{a})>0\right)$ and strategic complementarity $\left(v_{12}>0\right)$, or negative spillovers for $a=\bar{a}\left(v_{2}(\bar{a}, \bar{a})<0\right)$ and strategic substitutability $\left(v_{12}<0\right)$.

The action taken in the staggered game $\hat{a}$ is smaller than the action taken in the synchronised game $\bar{a}$ if the game exhibits positive spillovers for $a=\bar{a} \quad\left(v_{2}(\bar{a}, \bar{a})>0\right)$ and strategic substitutability $\left(v_{12}<0\right)$, or negative spillovers for $a=\bar{a}\left(v_{2}(\bar{a}, \bar{a})<0\right)$ and strategic complementarity $\left(v_{12}>0\right)$.

Proof :

See Appendix 2

Proposition 1 allows us to compare the magnitudes of action between the types of game. The two players clearly behave differently according to the time pattern of their interactions. Since each player has a non-negligible relative weight on the outcome of the game, in the staggered game, at the time one player acts, she has her hands tied-off, contrarily to the other player : she is a temporary leader. Henceforth, she has to care about the whole dynamic chain of future reactions to her decisions. In the synchronised game, as both players act simultaneously, this does not happen : there is no dynamic interaction.

Proposition 1 shows that both the type of spillovers and the nature of strategic interactions matter when comparing the synchronised and staggered outcomes. That makes sense. Consider player $i$ when she has to make a decision when (for example) the game exhibits strategic complementarity and negative spillovers at $(\bar{a}, \bar{a})$. Player $i$ knows that, if she increases (decreases) her action, relative to the synchronised decision, player $-i$ too will increase (decrease) her action next period, due to strategic complementarity, etc..., which has a negative (positive) discounted effect on her present payoff, because of the negative spillovers. Therefore, she decides to decrease her action. This reasoning goes on until an equilibrium is reached. 
We are then induced to look at the welfare implications of the two types of game. This is the purpose of the following proposition.

\section{Proposition 2:}

Both players get higher (lower) payoffs when they act sequentially than when they act simultaneously if, and only if, the game exhibits strategic complementarity (strategic substitutability).

Proof :

Let $a^{*}$ denote the symmetric cooperative equilibrium value of $a . a^{*}$ is the solution of the following program:

$$
\underset{a}{\operatorname{Max}} v(a, a)
$$

Therefore, the first-order condition of this program implies that :

$$
v_{1}\left(a^{*}, a^{*}\right)=-v_{2}\left(a^{*}, a^{*}\right)
$$

The solution $a^{*}$ and its corresponding payoff will be used as benchmarks for the welfare comparisons of $\hat{a}$ and $\bar{a} . \bar{a}, \hat{a}$ and $a^{*}$ are defined by eqs. (5), (A8)-(A9), and (12) respectively. Using the a method for comparing $\bar{a}, \hat{a}$ and $a^{*}$ similar to the one used in Appendix 2 to prove Proposition 1, entails :

- $\bar{a}<\hat{a}<a^{*}$ or $a^{*}<\hat{a}<\bar{a}$

if the game exhibits strategic complementarity;

- $\hat{a}>\bar{a}>a^{*}$ or $\hat{a}<\bar{a}<a^{*}$

if the game exhibits strategic substitutability.

The two conditions show that $\hat{a}$ (resp. $\bar{a}$ ) takes an intermediate value between $\bar{a}$ (resp. $\hat{a}$ ) and $a^{*}$ if there is strategic complementarity (resp. substitutability). The concavity of $v(a, a)$ implies that :

- $v(\hat{a}, \hat{a})>v(\bar{a}, \bar{a})$ if $\quad \bar{a}<\hat{a}<a^{*} \quad$ or $a^{*}<\hat{a}<\bar{a}$

i.e. if the game exhibits strategic complementarity; 
- $v(\hat{a}, \hat{a})<v(\bar{a}, \bar{a})$ if $\hat{a}>\bar{a}>a^{*}$ or $\hat{a}<\bar{a}<a^{*}$

i.e. if the game exhibits strategic substitutability. QED.

Proposition 2 gives a strikingly simple rule to assess the superiority of one game compared to the other : it only depends on the type of strategic interactions between the two players.

Again, let us illustrate this remark by means of the case with both negative spillovers at $(\bar{a}, \bar{a})$ and strategic complementarity. The non-cooperative synchronised game results in a too high action by the players, compared to the cooperative outcome. As we have seen, the staggering of decisions allows players 1 and 2 to decrease their actions, exploiting sequentially the existing strategic complementarity, therefore coming closer to the cooperative outcome : staggered decisions are Pareto-superior to synchronised decisions in this case. More generally, in the presence of spillovers, whatever the time pattern is, the result of the non-cooperative game is inefficient. But the staggering of decisions, in the case of strategic complementarity, allows the players to dynamically exploit the strategic interactions between agents and to achieve an outcome closer, in terms of welfare, to the cooperative equilibrium.

Hence, from this proposition, we may consider the time pattern of such games as a device to accommodate the coordination failures generated by spillovers, indeed clearly an imperfect mechanism de facto to coordinate the decisions of both agents. We develop this idea as we now turn to the issue of endogeneity of the timing of decisions.

Let us consider the case when timing is endogenous. Let us say that, before the actual game starts, the players play a "timing game", in which they choose whether to act in odd or in even periods. This game allows us to obtain a very simple device for modelling decisions to stagger or synchronise. The choices are made simultaneously with pure strategies and prior to the first period. Moreover, in order to avoid the issue of the dynamics of the game during the adjustment to the stationary equilibrium in the initial periods, once the equilibrium of the timing game has been determined, we assume that the stationary equilibrium is reached at the first period. We could study the dynamics of the game and show, in the spirit of Maskin and Tirole (1988a), that our results hold if the discount factor is close enough to one, since, in such case, the stationary equilibrium is determinant. These assumptions yield the following proposition :

\section{Proposition 3 :}


Players synchronise (stagger) their actions if and only if the game exhibits strategic substitutability (complementarity).

Proof:

Let us write the normal form of the timing game :

Player 2

\begin{tabular}{|c|c|c|c|}
\hline & & odd & even \\
\hline \multirow{2}{*}{$\begin{array}{c}\text { Player } \\
1\end{array}$} & odd & $v(\bar{a}, \bar{a}), v(\bar{a}, \bar{a})$ & $v(\hat{a}, \hat{a}), v(\hat{a}, \hat{a})$ \\
\hline & even & $v(\hat{a}, \hat{a}), v(\hat{a}, \hat{a})$ & $v(\bar{a}, \bar{a}), v(\bar{a}, \bar{a})$ \\
\hline
\end{tabular}

Proposition 3 implies that (even, even) and (odd, odd) are Nash equilibria if the game exhibits strategic substitutability and that (even,odd) and (odd, even) are Nash equilibria if the game exhibits strategic complementarity. QED.

We can now go further about the issue of the time structure of the game and analyse the consequences of the length of the period during which players cannot modify their actions when staggering is a non-cooperative equilibrium of the timing game. We can make the following proposition :

\section{Proposition 4:}

If players decide to stagger their actions, a decrease in the length of the period during which players cannot modify their actions increases (decreases) $\hat{a}$ if $v_{2}(\bar{a}, \bar{a})>0\left(v_{2}(\bar{a}, \bar{a})<0\right)$ and is Pareto-improving.

Proof : 
Let us denote by $\mathrm{T}$ the length of the period in which the actions are fixed, and $\mathrm{r}$ the discount rate of the players. Hence the discount factor is given by $\delta=e^{-r T}$. Differentiating eqs. (A8) and (A9) yields :

$$
\frac{d \hat{a}}{d \delta}=\frac{-v_{2}(\hat{a}, \hat{a}) v_{11} \beta}{\left(v_{11}+\beta \delta v_{21}\right)\left(v_{11}+\delta W^{\prime \prime}\right)}
$$

Proposition 3 has shown that players stagger their actions iff $\beta$ is positive. Moreover, $v_{11}+\beta \delta v_{21}<0$ (from eq.4), $v_{11}+\delta W^{\prime \prime}<0$ (from eq.10), $v_{11}<0$ (from eq.3). Therefore, $\partial \hat{a} / \partial \delta$ has the same sign as $v_{2}(\hat{a}, \hat{a})$. Since $v_{2}(\hat{a}, \hat{a})$ and $v_{2}(\bar{a}, \bar{a})$ have always the same sign (see Appendix 2), $\partial \hat{a} / \partial \delta$ has the same sign as $v_{2}(\bar{a}, \bar{a})$. From Proposition 2, we know that the symmetric cooperative equilibrium value, $a^{*}$, is larger (resp. smaller) than $\hat{a}$ if $v_{2}(\bar{a}, \bar{a})>0$, (resp. $\left.v_{2}(\bar{a}, \bar{a})<0\right)$. Thus an increase in $\delta$, corresponding to a decrease in T, brings $\hat{a}$ closer to $a^{*}$. QED.

Proposition 4 simply states that, in case of strategic complementarity, the more often (the quicker) agents play, the better off they are. Increasing the speed of the game when there is strategic complementarity, is a way to overcome the non-cooperative nature of the game. This is easy to understand. A decrease in the period length de facto amounts to an increase in the discount factor. Staggering decisions allows each agent to dynamically exploit the strategic complementarity effects so that she takes into account the existing spillover effects (see Proposition 1), and the individual welfare gain is higher the higher the discount factor is (the higher an agent cares about future) : as agents play more often, they are able to rip off the dynamic gains of staggering more often.

It is then obvious that a decrease in the period length has no effect when agents choose to synchronise (i.e. when there is strategic substitutability) because there is no never-ending dynamic chain of actions to be taken into account in such a time pattern.

The main result of this theoretical section is that, in a two-player setting, the time pattern of the game matters and can easily be assessed. First, the discrepancy between the actions taken in the two time patterns consistent with a two-period game, depends both on the existence of spillovers and strategic interactions. As such, this result, obtained for dynamic games, is close in spirit to the Cooper-John analysis of static games with strategic interactions. Secondly, the superiority of one time pattern over the other only depends on the nature of strategic interactions. The following section will apply these results to various conceivable economic games. 


\section{III - Some examples}

In this section, we shall discuss five dynamic games with Markov strategies played by two agents. The first two games have been already studied by Maskin-Tirole and De Fraja and we shall show how our propositions very easily allow us to reach annd extend their conclusions.

\section{a) Cournot duopoly competition}

We shall first analyse the case studied by Maskin and Tirole (1987) in their seminal paper on Cournot competition between two firms. Both firms compete through quantities on a given market. Each firm makes a decision (fixes a quantity to be sold on the market at each period) valid for two periods. They play sequentially. Both strategies are Markov strategies. The objective of a firm is to maximise the present discounted value of its future profits. At time $t$, firm i's instantaneous profit $\pi^{t}$ is a function of both firms's current quantities :

$$
\pi^{i}=\pi\left(q^{i}, q^{-i}\right) \quad i=1,2
$$

Maskin and Tirole assume that both demand function and production costs are linear, implying :

$$
\pi_{2}^{i}<0 \quad \pi_{22}^{i}=0 \quad \pi_{11}^{i}<0 \quad \pi_{12}^{i}<0 \quad i=1,2
$$

Hence, using the definitions given in the previous section, there are negative spillovers and strategic substitutability, as in standard Cournotian competition:

For any $\delta$, there is a unique stable Markov perfect Equilibrium to the staggered game, given the linearity of the demand and cost functions (Maskin and Tirole's Proposition (1)) and we may immediately derive from the previous section the two main steady-state propositions made by Maskin and Tirole .

- the steady-state output is bigger when firms stagger their decisions than when they synchronise (from our Proposition 1; equivalent to Maskin and Tirole's eq.(23), 1987, p.955))

- both firms would be better-off if they chose to synchronise, when playing the "timing game" (from our Proposition 3; see Maskin and Tirole's section 6, 1987, p.962-963). 
Our Proposition 4 does not apply here since the current game relies on strategic substitutability. But Maskin and Tirole remark that, in this game, when period duration is arbitrarily close to zero, the steady state output will converge to the competitive output, concluding that "the relative timing of firm's moves matters crucially, even in the limit when firms react very quickly... [and that] the distinction between simultaneous and alternating moves remains important even when T is small", which also is the qualitative message of Proposition 4.

\section{b) Union-wage setting games}

De Fraja (1993) used Market Perfect Equilibria to compare the relative performances of synchronised and staggered union-bargained wages. In De Fraja's model, two firms compete à la Cournot on a good market, fixing the quantities every period, and wages are set by two firm-specific unions. But the duration of the wage contract is two periods. We shall show that, thanks to Proposition $1-4$, it is very easy to obtain the results highlighted by De Fraja, escaping the tedious algebraic computations of the explicit solutions he offers, following Maskin and Tirole (1987).

Let us summarize the crucial elements of De Fraja's model. De Fraja assumes that there are two trade unions (one in each firm), each one maximising the total amount of rent available for its workers. The labour demands are derived from profit maximisation, the market demand function is linear and there are constant returns to scale. Hence, the trade-union instantaneous objective is defined as :

$$
U\left(w^{i}, l^{i}\right) \equiv\left(w^{i}-r\right) \cdot l^{i}
$$

with : $l^{i}=l\left(w^{i}, w^{-i}\right) \quad i=1,2$

$$
l_{1}\left(w^{i}, w^{-i}\right)<0 \quad l_{2}\left(w^{i}, w^{-i}\right)>0 \quad l_{12}\left(w^{i}, w^{-i}\right)=l_{11}\left(w^{i}, w^{-i}\right)=l_{22}\left(w^{i}, w^{-i}\right)=0
$$

$w^{i}$ is the wage paid by firm $i, r$ is the reservation wage, and $l^{i}$ is firm $i^{\prime} \mathrm{s}$ employment. Then the instantaneous payoff function for union $i$ can be written as

$$
v\left(w^{i}, w^{-i}\right)=\left(w^{i}-r\right) \cdot l\left(w^{i}, w^{-i}\right)
$$

with :

$$
v_{2}\left(w^{i}, w^{-i}\right)=\left(w^{i}-r\right) \cdot l_{2}>0 \quad v_{22}=0
$$




$$
v_{12}=l_{2}>0
$$

For any $\delta$, conditions for stability and unicity of the solution to the staggered game are fulfilled (De Fraja's Proposition (2)) and applying Propositions 1 and 2 immediately shows that staggered wage setting entails higher wages and higher payoffs to the unions (De Fraja's Proposition 3), since there are both positive spillover effects (a higher wage for firm 2 means a relatively more competitive firm 1 , therefore more employment in firm 1 , and hence a higher total rent obtained by union 1) and positive strategic complementarities (a catch-up effect between unions). From Proposition 3, it is deduced that unions should stagger their decisions, even if it is bad for employment. Finally, Proposition 4 implies that a decrease in the length of (still biperiodic) wage contracts increases wages and unions's payoffs (De Fraja's Corollary 1).

Furthermore, we can extend De Fraja's results to include the aggregate side-effects of union-wage bargaining which are neglected by De Fraja. In De Fraja's framework, the pair of firms typically compete on a local market without aggregate side-effects : they are implicitly assumed to be very small. In particular, their behaviours have no impact on the aggregate price level. Now let us consider industries producing differentiated goods consumed by identical consumers with wage bargaining taking place at industry level. It is to be noticed that this is the case in many OECD countries like Austria, Belgium, France, Germany or the Netherlands. In such a setting, there exists another channel of interaction between firms, and hence between unions, through consumer demands and relative good prices. Does that modify De Fraja's conclusions?

In order to address this issue, we shall concentrate on inter-industry competition, instead of intra-industry competition. Let us consider a highly stylized economy. In this economy, there are two industries, producing two different goods, consumed by identical consumers. The preferences of the representative consumer are represented by the following utility function :

$$
\left.U\left(C_{1}, C_{2}\right)=C_{1}^{\frac{\alpha}{2}} C_{2}^{\frac{\alpha}{2}}\left(\frac{M}{P}\right)^{1-\alpha} \quad \alpha \in\right] 0,1[
$$

where $C_{i}$ is the quantity of good $i, \mathrm{i}=1,2, \mathrm{M}$ is the quantity of money and $\mathrm{P}$ is the consumer price index, defined as :

$$
P=\left(P^{1}\right)^{\frac{1}{2}}\left(P^{2}\right)^{\frac{1}{2}}
$$

where $P^{i}$ is the price of good $i$. 
The consumer is endowed with a given money stock denoted by $M^{*}$ and profits are equally redistributed. Hence, the demand for good $i$ is defined by :

$$
Q^{i}=\frac{\alpha}{1-\alpha} \frac{M^{*}}{2 P^{i}} \equiv \frac{B}{P^{i}}
$$

In each industry, there are competitive firms with unit constant return to scale. Hence the equilibrium price is :

$$
P^{i}=W^{i}
$$

where $W^{i}$ is the nominal wage in industry $i$. A unique union is able to determine the nominal wage in effect in a given industry. In a static game, the objective of union $i$ is to maximise the following objective function :

$$
S^{i}=-\frac{1}{2}\left(q^{i}-\bar{n}\right)^{2}-\frac{1}{2}\left(w^{i}-p-\bar{w}\right)^{2}
$$

where $\bar{n}$ and $\bar{w}$ are exogenous employment and wage targets, and lower-case letters denote logs of corresponding variables. Trade-unions are compelled to fix a nominal wage for two periods. Using the definition of the equilibrium prices, the price index and the demand functions, union's $i$ instantaneous payoff can be written as :

$$
v\left(w^{i}, w^{-i}\right)=-\frac{1}{2}\left(b-w^{i}-\bar{n}\right)^{2}-\frac{1}{2}\left(\frac{w^{i}}{2}-\frac{w^{-i}}{2}-\bar{w}\right)^{2}
$$

Hence :

$$
\begin{aligned}
& v_{2}=\frac{1}{2}\left(\frac{w^{i}}{2}-\frac{w^{-i}}{2}-\bar{w}\right) \quad v_{22}=-\frac{1}{4} \\
& v_{11}=-\frac{5}{4} \quad v_{12}=\frac{1}{4}
\end{aligned}
$$

One can check that there exist a unique stable MPE in the staggered game, according to the lemma, if the discount factor $\delta$ is larger than $\frac{1}{3}$. In this case, $P(\beta)$ is such that $P(1)<0, P(-1)>0$ and $P^{\prime}(\beta)<0, \beta \in[-1,1]$.

In brief, at the steady state, the dynamic game now exhibits negative spillovers and strategic complementarity. We are then able to apply our theoretical propositions and immediately make the following statements : 
i) The steady state level of wage is lower in a staggered setting than in a synchronised one; game;

ii) Staggering emerges as a non-cooperative equilibrium of the timing

iii) A decrease in period duration decreases nominal wages and increase employment.

Results $i$ ) and iii) are opposed to the results obtained by De Fraja for the intra-industry competition case. In other words, both intra- and inter-industry competitions matter and have opposite effects on the relative importance of staggered nominal wages compared to synchronised ones, even though staggering is always best from the point of view of unions.

\section{c) Input games}

Input games have already been studied by Cooper and John in a static framework. Here we develop a dynamic version of this game, exhibiting dynamic strategic interactions. There are two identical players, each supplying one input to a joint production process. We note $e^{i}$ the "effort" level supplied by Player $i$ ( $i=$ $1,2)$. The resulting product derives from the following production function :

$$
y=f\left(e^{1}, e^{2}\right)=e^{1} e^{2}
$$

Notice that there are positive technical complementarities within the production process, i.e. : $f_{12}>0$.

The utility function of Player $i$ depends both on $y$ and $e^{i}$ as follows :

$$
\begin{aligned}
& \dot{U}\left(y, e^{i}\right)=k y-\left(e^{i}\right)^{2} \\
& 1>k>0
\end{aligned}
$$

It is assumed that Player i commits herself to two periods, i.e. chooses and plays $e^{i}$ for two periods.

Examples of input games abound. Let's think to all kinds of team or club activities or supply of public goods, e.g. :

1 - militancy of two political leaders, belonging to the same party, yet competitors within the party (Gladstone and Disraeli in Victorian Great Britain, Chirac and 
Balladur in contemporary France) : each leader has to decide on her level of political activity $\left(e^{t}\right)$, the outcome for the party (ratings in polls, probabilities of success in elections, etc...) depending on both levels;

2 - joint pollution processes : along a lake there are two polluters (countries like the US and Canada sharing the Great Lakes, cities or factories), $e^{i}$ is the level of pollution-control efforts made by player (polluter) $i$, whereas $y$ is the level of lake-water quality, depending on the efforts made by both polluters;

3 - a fiscal game within a political union: Two countries belong to a political union and have non cooperatively to decide on the level of their voluntary contribution $\left(e^{t}\right)$ to the budget of the Union ${ }^{2}$, the result achieved by the Union, (y), depending in a non-linear manner on these two contributions.

4 - space exploration: The US and the late USSR have embarked in huge, longlasting programs of space exploration. Competition has manifested catch-up effects with temporary leadership for each country (Soviet sputnik, American Appollo, Soviet Mir orbital station, American Challenger Shuttle). Clearly, space knowledge is a public good, benefiting from both efforts.

Then the questions we ask are :

1 - Should party leaders synchronise or not their appearance on TV shows?

2 - Will polluters be more active cleaning the lake when they act sequentially rather than simultaneously, and should they act sequentially or not (one in winter, the other in summer)?

3 - Will the two countries channel more money to the Union when they decide on budget matters sequentially rather than simultaneously, and should they do so?

4 - Can we assess the efficiency of the space competition time pattern between the two super-powers?

From eqs. (27) - (28), the instantaneous payoff function of player $i$ can be written as :

$$
v\left(e^{i}, e^{-i}\right)=k e^{i} e^{-i}-\left(e^{i}\right)^{2}
$$

\footnotetext{
${ }^{2}$ Some readers might argue that behaviours within a political union should be cooperative. Let's say that we consider here a "realistic" assumption of non-cooperative behaviour.
} 
The strategic interaction effect, $v_{12}$, is obtained by differentiating the payoff function :

$$
v_{12}=k
$$

whereas the spillover effect, $v_{2}$, is equal to :

$$
v_{2}\left(e^{i}, e^{-i}\right)=k e^{i} \quad v_{22}=0
$$

There is always a unique stable MPE in the staggered game since $P(-1)>0, \quad P(1)<0, \quad P(0)>0$ and there is one unique root between 0 and 1 ;.

Both effects are positive, and in particular, the game exhibits positive strategic complementarity. Therefore, we immediately conclude that :

- the action decided by each player is larger when they stagger than when they synchronise their decisions:

- and they should stagger their decisions.

For example, if we agree that space competition knowledge benefits from large technical complementarities (and can be formalized by the present game) ${ }^{3}$, we conclude that the Soviet-American space competition time pattern was the most efficient one, of course given the fact that both players could not behave cooperatively.

These statements directly derive from Propositions 1 - 3 .

\section{d) An international monetary game}

Although monetary policy is rather flexible, especially compared to fiscal policy, governments are not able (or willing) at each period (as small as we wish) to switch the monetary policy course and alter their last period decision. Indeed, monetary economists distinguish "phases" or "episodes" of monetary policy, usually expanding over several terms, if not several years. Various factors may explain that monetary authorities do want to stick to a given policy stance over several periods : a desire to commit themselves and gain credibility, a desire to stabilize over-zealous, over-reacting financial markets, a relative inability to trace down the actual evolution of the economy, etc...In the meantime, in the international economy, the various monetary authorities usually do not cooperate, even though some act as followers relative to others. Moreover, they do not

${ }^{3}$ Of course, other, more complex, input games would generate the same result. 
appear as acting "simultaneously", issuing "statements" or making decisions at the same time. Thus, the question arises to assess the impact of the time pattern of monetary decisions : is it efficient? Does it induce the non-cooperating players to over- or under-react?

We shall offer a first tentative answer to these questions by means of a highly stylized example which will allow us to consider and compare the perfect Markov equilibria of the game : we shall assume a two-country economy, where both monetary authorities commit themselves to two periods, and study the monetary game arising in this setting.

The two countries are interrelated in such a way that the output in one country depends both on the domestic and foreign money supplies. Hence spillovers exist between both countries. Canzoneri and Gray (1985) list four possible channels underlying these spillover effects : a Mundellian interest-rate channel, a goods demand channel, an indexation channel and an import price sluggishness channel. They stress the fact that the resulting spillovers may either be positive or negative ${ }^{4}$.

The two countries are identical. In order to make the application of the theoretical results more straightforward, we shall index the two countries 1 and 2, rather than talk about "domestic" and "foreign" countries. The reduced-form equations for outputs in the world economy are given by the following equations :

$$
y^{i}=\theta y^{N}+A m^{i}+B m^{-i} \quad i=1,2
$$

where $y^{1}\left(y^{2}\right)$ is (the rate of growth of) aggregate output of country $1(2), m^{1}\left(m^{2}\right)$ is (the rate of growth of) money supply in country 1 (2), $y^{N}$ is the natural (rate of growth of) output. Aggregate output is a function of target output and both money supplies. As in Gibbons (1992), it is supposed that target ouput is less than natural output $(\theta<1)$ because of the presence of monopoly power in goods markets.

We assume that monetary authorities perfectly control the domestic inflation rate (cf Dolado et al. (1994)), i.e. :

$$
\pi^{i}=m^{i}
$$

A is always positive and B may either be positive or negative, but always smaller in absolute value to $\mathrm{A}$.

${ }^{4}$ See Frankel (1988) for an empirical evaluation of these channels. 
The instantaneous preferences of both governments or monetary authorities are assumed to be identical:

$$
v^{i}=-\frac{1}{2}\left[\left(y^{i}-y^{N}\right)^{2}+\mu\left(\pi^{i}\right)^{2}\right] \quad \mu>0
$$

Governments dislike variations of actual output around natural output and inflation rates different from zero. Of course, these two goals are antagonistic, implying that governments face a policy trade-off : they could decrease the output gap at the expense of an increase in inflation rate above its desired zero level. Both governments are supposed to chose their money supply non-cooperatively.

From eqs. (32) - (34), the following instantaneous payoff function obtains :

$$
v\left(m^{i}, m^{-i}\right)=-\frac{1}{2}\left[\left((\theta-1) y^{N}+A m^{i}+B m^{-i}\right)^{2}+\mu\left(m^{i}\right)^{2}\right]
$$

The spillover effect is equal to :

$$
v_{2}\left(m^{i}, m^{-i}\right)=-B\left[(\theta-1) y_{N}+A m^{2}+B m^{-i}\right]
$$

whereas the strategic effect is equal to 5 :

$$
v_{12}=-B A
$$

When B is positive, the spillover effect happens to be negative and the model exhibits strategic substitutability. Since an increase in foreign money supply supports domestic output, domestic monetary authorities are induced to give more attention to their other goal, namely inflation fight, and henceforth, to decrease their own money supply. There is a unique stable MPE of the staggered game when $\delta$ is smaller than $\left(A^{2}+\mu\right)(4 B A)^{-1}$ since then, $P(1)<0, \quad P(-1)>0, \quad P(0)<0$ and $\left.P^{\prime}(\beta)<0, \quad \beta \in\right]-1,1[$. Then we may state that :

(i) non-cooperative decisions are stronger when they are staggered than when they are synchronised;

(ii) governments, even though they do not cooperate, would be better off if they simultaneously made their decisions.

This is fair enough : due to the negative spillovers, both non-cooperative actions are too big compared to the cooperative efficient one. Since

\footnotetext{
${ }^{5}$ Remark that $\left|v_{11}\right|=A^{2}+\mu>\left|\delta v_{22}\right|=\delta B^{2}$.
} 
synchronisation allows the two players to decrease their money supply, this time pattern should be preferred by both monetary authorities.

But this result is reversed when B is negative, as in a beggar-thy neighbor world. Let us assume that this is the case :

$$
B<0 \quad|B|<A
$$

Then the model exhibits strategic complementarity between both countries : an increase in $m^{-i}$ decreases $y^{i}$ and induces player $i$ (that is, monetary authorities in country $i$ ) to compensate this effect and to increase $m^{i}$. There is a unique stable MPE to the staggered game when $\left(A^{2}+\mu\right)(-4 B A)^{-1}>\delta>(A(A+B)+\mu)(-B(A-B))^{-1}$ since then $P(1)<0, \quad P(-1)>0$, $P(0)>0$ and $\left.P^{\prime}(\beta)<0, \quad \beta \in\right]-1,1[$.

Then :

(i) staggered decisions are weaker than synchronised ones as both countries dynamically exploit the strategic complementarity link,

(ii) governments should then stagger their decisions, given the negative spillovers, since weaker decisions are to be preferred.

What can we deduce from these results?

Let us consider a plausible interdependance effect, through technical integration (corresponding to Canzoneri and Gray's goods demand channel), and assume that presently, the French and German economies are closely enough interrelated as to exhibit technical complementarities (through ventures yesterday like Airbus, now ventures in banking, insurance, broadcasting, telecoms, financial services) such that the B coefficient for both countries is positive. That induces us to conclude that they should strive to synchronise their monetary decisions (which they increasingly do $)^{6}$. Of course, it is likely that such synchronisation is the first step to a closer monetary integration, leading to a common currency.

On the other hand, we may think that such a production integration has not taken place between UK and Germany, given the fact that the British economy has specialized in services, with a shrinking industrial sector, whereas Germany is still a major industrial power, or between the US and Germany, the two leading transatlantic monetary actors. These two couples are then supposedly characterized by a negative $\mathrm{B}$ coefficient (ceteris paribus). It is then no wonder

${ }^{6}$ assuming that the conditions of the lemma are verified. 
that they do not try to synchronise their monetary process, and we may venture that UK is not ready to go along with a unique European currency.

\section{e) A trade game}

Let us then consider a trade policy game played by two governments through export subsidies. An important advance recently made in international trade theory is the integration of imperfect competition in international trade. A natural outcome has then been the study of trade policies, implemented by national governments in the context of imperfect international competition. Actually, "trade wars" (between Japan and the US on cars, between Europe and US on aircrafts,etc...) take place between a small number of players, within oligopolistic industries (typically with a national "champion", eg. Airbus and Boeing) and extend over months or years, through a lengthy retaliation process 7 . Policy measures typically last for several terms or even years and the issue of the time pattern of a given trade war becomes of major importance. It is clear that interventions, statements by heads of national trade policy bureaus (eg. Clara Hill or Mickey Cantor for the US, Leon Brittan for Europe) are carefully prepared, if not planned and have lasting effects. However, the various studies devoted to the issue of trade policy games skip over that fact and usually consider one-period (possibly with several stages) games. Perfect Markov Equilibria allow us to go beyond that stage and assess the implications of the time pattern of trade wars 8 .

In order to do this, we shall extend the original classic Brander and Spencer (1985) framework of an export subsidy game, played by two governments and assume that each government chooses its level of export subsidy for two periods, due to decisional rigidities of various kinds (existence of implementation costs, desire to gain credibility through commitment, existence of two-periods plans for investment and production at the firm level, etc...)

Consider an industry, in which two firms, belonging to two different countries, produce a given good, sold only on a third market. At each period, the two firms compete on quantities, à la Cournot. Each government is able (and willing) to give subsidy to its national firm, in order to sustain its exports and hence gain market share on the third country's consumer market. Each government is able to act first, relative to its national firm. We assume that governments never subsidise on such levels that the firm would be unprofitable without the subsidy. As said by Brander and Spencer, "firms play Nash against all other players, and governments play Stackelberg against firms, and Nash against

\footnotetext{
${ }^{7}$ For a recent survey on this issue, see Krishna and M. Thursby (1990).

${ }^{8}$ Tanaka (1994) is the exception, since he studies a dynamic Cournot duopoly with export subsidies, where each firm commits its offered quantity to two periods, and solves the MPE of this game. Our own example, however, will be different from his game.
} 
other governments" (Brander and Spencer (1985)). Notice that the scheme is actually similar to the de Fraja (1993) setting.

We index firms and governments by 1 and 2 (again rather than the standard "national" and "foreign"). Both firms are technologically identical. Each firm maximises its profit $\pi^{i}, \mathrm{i}=1,2$ :

$$
\pi^{i}\left(q^{i}, q^{-i}, s^{i}\right)=q^{i} p\left(q^{i}+q^{-i}\right)-c\left(q^{i}\right)+s^{i} q^{i} \quad i=1,2
$$

where $q^{i}$ is the production/export level of firm $i, p(\cdot)$ is the inverse demand function for the good, $c($.$) is the cost function, and s^{i}$ is the per-unit subsidy given by government $i$. The inverse demand function is decreasing and linear :

$$
p\left(q^{1}+q^{2}\right)=D-\left(q^{1}+q^{2}\right) \quad D>0
$$

and there is a constant marginal cost :

$$
c\left(q^{i}\right)=c q^{i} \quad D>c>0
$$

Then immediately, the instantaneous output level chosen by firm $i(i=1,2)$ is equal to :

$$
q^{i}=\frac{D+s^{i}-c-q^{-i}}{2}
$$

Hence $q^{i}$ is a function of $s^{i}$ and $s^{-i}$ :

$$
q^{i}=q\left(s^{i}, s^{-i}\right)=A+\frac{2}{3}\left(s^{i}-\frac{1}{2} s^{-i}\right)
$$

with : $A=\frac{D-c}{3}$

$$
q_{1}^{i}=\frac{2}{3}>0 \quad q_{2}^{i}=-\frac{1}{3} \quad\left|q_{1}^{i}\right|>\left|q_{2}^{i}\right|
$$

These conditions guarantee the stability of the Nash equilibrium and are equivalent to the Brander and Spencer conditions (see Brander and Spencer (1985), p.87).

Each government, through its subsidy decision, wants to maximise the present value of discounted net domestic surpluses. $v\left(s^{i}, s^{-i}\right)$, the instantaneous 
payoff for government $i$, is defined as the profit of the domestic firms minus the cost of the subsidy :

$$
v\left(s^{i}, s^{-i}\right)=\pi^{i}\left(q^{i}, q^{-i}, s^{i}\right)-s^{i} q^{i}=q^{i} p\left(q^{i}+q^{-i}\right)-c\left(q^{i}\right)
$$

Notice that all strategic and spillover effects go through the indirect impact of $s^{-t}$ on $q^{-i}$, hence on $p$. Substituting eqs.(40),(41) and (43) in eq.(45), we obtain a quadratic formula for the instantaneous payoff function :

$$
v\left(s^{t}, s^{-1}\right)=A^{2}+\frac{A}{3}\left(s^{t}-2 s^{-1}\right)-\frac{2}{9}\left[\left(s^{t}\right)^{2}+\frac{1}{2}\left(s^{t}\right)\left(s^{-1}\right)-\frac{1}{2}\left(s^{-1}\right)^{2}\right]
$$

The spillover effect, $v_{2}^{i}$, is equal to :

$$
\begin{aligned}
v_{2}\left(s^{i}, s^{-i}\right) & =p q_{2}^{i}+q^{i} \cdot p^{\prime} \cdot\left(q_{2}^{i}+q_{1}^{-i}\right)-c \cdot q_{2}^{i}=(p-c) q_{2}^{i}+q^{i} \cdot p^{\prime} \cdot\left(q_{2}^{i}+q_{1}^{-i}\right) \\
& =-\frac{2 A}{3}-\frac{s^{i}}{9}+\frac{2 s^{-i}}{9}
\end{aligned}
$$

which is negative because of imperfect competition and eq.(44). That is what was expected. An increase in foreign subsidies augments the market share of the foreign firm and diminishes the domestic production and export and the market price. Hence, the profit made out by less sale for a given mark-up diminishes so as the gain made at a smaller price for a given production level decreases. Globally, the surplus is reduced.

The strategic interaction effect, $v_{12}$, is equal to:

$$
v_{12}=q_{2}^{-1} \cdot q_{2}^{1} \cdot p^{\prime}=-\frac{1}{9}
$$

which is negative. This is common sense : remember that the net effect of the domestic subsidy on the instantaneous payoff is through price variation. As foreign government increases its export subsidy, increasing foreign production and proportionately decreasing the price level, the marginal net return of domestic subsidy decreases. Hence, domestic government is induced to reduce its own subsidy in order to regain a more profitable price level even though it means a further reduction in production and export. There is a unique stable solution to the dynamic game for any $\delta \in] 0,1[$ since then, $P(1)<0, \quad P(0)<0, \quad P(-1)>0$ and the two inflexion points correspond to positive $\beta^{9}$.

${ }^{9}$ Remark that $\left|v_{11}\right|=\frac{4}{9}>\left|\delta v_{22}\right|=\delta \frac{2}{9}$. 
Thus, we are able to make the following statement about hypothetical "trade wars":

(i) A trade war is more severe when it is played sequentially rather than simultaneously. That is, the level of export subsidies is higher when each player is a (temporary) leader, as it tries to use its temporary freedom to gain a larger market share at the expense of its competitor;

(ii) Everybody 10 would then be better off if a non-cooperative "trade war" were played simultaneously rather than sequentially. Indeed, as trade subsidies are individual responses to other's subsidies in order not to lose market share and are deteriorating joint welfare, synchronisation of decisions which would result in smaller export subsidies would benefit both competitors. This is well in accordance with the standard Brander and Spencer result that "joint welfare would rise if subsidy levels were reduced" (Proposition 5, Brander and Spencer (1985), p.95) and with the intuitive opinion about the worsening effects through escalation/retaliation measures of sequential episodes of trade wars.

\section{IV - Conclusion}

The basic qualitative result to be drawn from this paper is that spillovers and strategic interactions between agents are determinant for the study of various time patterns of mutiperiodic decisions. Restricting the analysis to a simple alternative between two time patterns (synchronisation versus staggering), we offered strikingly simple rules allowing us to make precise statements about these two time patterns. In particular, we showed that the non-cooperative choice of a given time pattern is a way to reduce the inefficiencies arising from existing externalities when agents do not cooperate. In other words, such a choice appears as a non-cooperative mechanism to partially overcome the disadvantages of noncooperation.

We then offered several examples, either of a micro- or a macroeconomic nature, and applied the rules obtained for the abstract game. In real world, examples when actions are pre-committed to several periods, i.e. last, abound. It is clear that a presidential strategy, a space research programme, a trade policy, an advertising campaign (the list is not exhaustive), are carefully planned and extended over time. Hence, the issue of time patterns of decisions is not a trivial one. Our propositions allow us to make precise statements on the issue of timing in the various games we selected.

Our analysis has been restricted to a deterministic framework with identical players. It would be interesting to extend the analysis to a stochastic world. It is likely that the nature of shocks will affect the comparison between different time

${ }^{10}$ This is true also for the two firms since their welfare is positively tied to the government's welfare. 
patterns, along with externalities and strategic interactions. The case with heterogeneous agents, with different payoff functions should also be considered, in order to prove the generality of the importance of strategic interactions in dynamic games with pre-commitments.

\section{References}

Brander J. A. and B. J. Spencer (1985), "Export subsidies and international market share rivalry", Journal of International Economics, vol.18, 85-100.

Canzoneri M. B. and J. Gray (1985), "Monetary policy games and the consequences of non-cooperative behaviour", International Economic Review, $26,547-564$.

Cooper R. and J. Haltiwanger (1992), "Macroeconomic implications of production bunching. Factor Demand linkages", Journal of Monetary Economics $30,107-127$.

Cooper R. and J. Haltiwanger (1993), " The aggregate implications of machine replacement : Theory and Evidence", American Economic Review, 83, 360 - 382.

Cooper R. and A. John (1988), "Coordinating coordination failures in Keynesian models", Quarterly Journal of Economics, 103, 441 - 463.

De Fraja G. (1993), " Staggered vs synchronised wage setting in duopoly"官 European Economic Review, 37, 1507 - 1522.

Dolado J. J., M. Griffiths and A. J. Padilla (1994), "Delegation in internationaP monetary policy games", European Economic Review, 38, 1057 - 1069.

Fischer S. (1977), "Long-term contracts, rational expectations and the optimal money supply rule", Journal of Political Economy, 85, 163-190.

Frankel J. (1988), " Obstacles to international macroeconomic policy coordination", IMF working Paper n.87/28.

Fudenberg D. and J. Tirole (1992), Game Theory, Cambridge, Mass.: MIT Press.

Gibbons R. (1992), Game Theory for Applied Economists, Princeton : Princeton University Press. 
Krishna K. and M. Thursby (1990), "Trade policy with imperfect competition : a selective survey", in C. Carter, A McCalla and J. Sharples (eds), Imperfect Competition and Political Economy, Boulder: Westview Press, 9 - 36.

Maskin E. and J. Tirole (1987), " A theory of dynamic oligopoly. III : Cournot Competition", European Economic Review, 31, 947 - 968.

Maskin E. and J. Tirole (1988a), " A theory of dynamic oligopoly. I : Overview and quantity competition with large fixed costs", Econometrica, 56, 549 - 569.

Maskin E. and J. Tirole (1988b), " A theory of dynamic oligopoly. II : Price competition, kinked demand curves and Edgeworth cycles", Econometrica, 56, $570-599$.

Tanaka Y. (1994), "Export subsidies under dynamic duopoly", European Economic Review, 39, 1139-1151.

Taylor J. B. (1980), "Aggregate Dynamics and staggered contracts", Journal of Political Economy, 88, 1-23.

Appendix 1

Differentiating eq.(9) implies :

$$
\frac{d R^{i}\left(a^{i}\right)}{d a^{-i}}=\frac{-v_{12}}{v_{11}+\delta W^{\prime \prime}\left(R^{i}\left(a^{-i}\right)\right)}
$$

The function $W^{i}\left(a^{i}\right)$ can be defined substituting eq.(6) in eq.(8) :

$$
W^{i}\left(a^{i}\right)=v\left(a^{i}, R^{-i}\left(a^{i}\right)\right)+\delta v\left(R^{i}\left(R^{-i}\left(a^{i}\right)\right), R^{-i}\left(a^{i}\right)\right)+\delta^{2} W^{i}\left(R^{i}\left(R^{-i}\left(a^{i}\right)\right)\right)
$$

Then, assuming that $R^{i}: a^{-i} \mapsto R^{i}\left(a^{-i}\right)=\alpha^{i}+\beta^{i} a^{-i}$ :

$$
\begin{aligned}
W^{\prime}\left(a^{i}\right)= & v_{1}\left(a^{i}, R^{-i}\left(a^{i}\right)\right)+v_{2}\left(a^{i}, R^{-i}\left(a^{i}\right)\right) \cdot \beta^{-i}+\delta v_{1}\left(R^{i}\left(R^{-i}\left(a^{i}\right)\right), R^{-i}\left(a^{i}\right)\right) \cdot \beta^{-i} \beta^{i} \\
& +\delta v_{2}\left(R^{i}\left(R^{-i}\left(a^{i}\right)\right), R^{-i}\left(a^{i}\right)\right) \cdot \beta^{-i}+\delta^{2} W^{\prime}\left(R^{i}\left(R^{-i}\left(a^{i}\right)\right)\right) \cdot \beta^{-i} \beta^{i}
\end{aligned}
$$

and : 


$$
\begin{aligned}
W^{\prime \prime}\left(a^{i}\right)= & v_{11}+2 v_{12} \beta^{-i}+(1+\delta) v_{22}\left(\beta^{-i}\right)^{2}+\delta v_{11}\left(\beta^{-i} \beta^{i}\right)^{2} \\
& +2 \delta v_{21}\left(\beta^{-i} \beta^{i}\right)^{2}+2 \delta v_{21}\left(\beta^{-i}\right)^{2} \beta^{i}+\delta^{2} W^{i \prime}\left(R^{i}\left(R^{-i}\left(a^{i}\right)\right)\right)\left(\beta^{i} \beta^{-i}\right)^{2}
\end{aligned}
$$

Eq.(A4) together with the linearity of $R^{i}\left(a^{-i}\right)$ implies that $W^{i \prime \prime}\left(a^{i}\right)=0$. Thus $W^{\prime \prime}\left(a^{i}\right)$ is a constant, denoted by $W^{\prime \prime}$.

Substituting the value of $W^{\prime \prime}$ given by eq.(A4) into eq.(A1), with $\frac{d R^{\prime}\left(a^{-1}\right)}{d a^{-1}}=\beta^{1}$ yields

$$
\beta^{i} v_{11}(1+\delta)+2 \beta^{i} \beta^{-i} \delta v_{12}+\left(\beta^{-i}\right)^{2} \beta^{i} \delta(1+\delta) v_{22}+\delta^{2} v_{12}\left(\beta^{i}\right)^{2}\left(\beta^{-i}\right)^{2}+v_{12}=0
$$

The system defined by eq.(A5) has both symmetric and asymmetric solutions. Substracting the two equations defined by eq. (A5) yields :

$$
\left(\beta^{1}-\beta^{2}\right)\left(v_{11}+\beta^{1} \beta^{2} \delta v_{22}\right)=0
$$

If $v_{22}=0$, eq. (A6) implies : $\beta^{1}=\beta^{2}=\beta$

If $v_{22}=0$ and there is an asymmetric solution $\left(\beta^{1} \neq \beta^{2}\right)$, eq. (A6) yields :

$$
\beta^{1} \beta^{2}=-\frac{v_{11}}{\delta v_{22}}
$$

If $\left|\frac{v_{11}}{\delta v_{22}}\right|>1$, the asymmetric equilibria are necessarily unstable since $\left|\beta^{\prime} \beta^{2}\right|>1$ and can be ruled out. The symmetric solution can then be directly derived from eq. (A6) and we obtain :

$$
\beta^{4} \delta^{2} v_{12}+\beta^{3} \delta(1+\delta) v_{22}+2 \beta^{2} \delta v_{12}+\beta v_{11}(1+\delta)+v_{12}=0
$$

Appendix 2 - Proof of Proposition 1.

At steady-state equilibrium, where $a^{i}=a^{-i}=\hat{a}$, the definition of $W^{\prime}(a)$ (given by eq.(A3) in Appendix 1) yields : 
$W^{\prime}(\hat{a})=\frac{v_{1}(\hat{a}, \hat{a})\left(1+\beta \delta^{2}\right)+v_{2}(\hat{a}, \hat{a})(1+\delta) \beta}{1-\beta^{2} \delta^{2}}$

Substituting this expression for $W^{\prime}(\hat{a})$ into the first-order condition (eq.(9)) gives :

$$
v_{1}(\hat{a}, \hat{a})=-\beta \delta v_{2}(\hat{a}, \hat{a})
$$

with :

$$
\left.\beta=\frac{-v_{12}}{v_{11}+\delta W^{\prime \prime}} \quad \in\right]-1,1[
$$

$\bar{a}$ and $\hat{a}$ are defined by eq.(5) and eqs.(8)-(A9) respectively.

The stability condition for the synchronised game (eq.(4)) implies that $v_{1}(a, a)$ is a linear decreasing function with a slope equal to $v_{11}+v_{12}<0 . v_{2}(a, a)$ is a linear function, with a slope equal to $v_{12}+v_{22} . v_{2}(a, a)$ can be either increasing or decreasing.

Case 1: We suppose $v_{2}(a, a)$ is increasing, ie $v_{21}+v_{22}>0$.

In order to compare $\bar{a}$ and $\hat{a}$, we have to distinguish two subcases :

Case 1.1 : Strategic complementarity: $v_{12}>0$

If $v_{12}>0, \beta>0$ and $-\beta \delta v_{2}(a, a)$ is decreasing, with a slope $-\beta \delta\left(v_{12}+v_{22}\right)<0$. The slope of $v_{1}(a, a)$ is larger, in absolute value than the slope of $-\beta \delta v_{2}(a, a)$ since :

$v_{11}+v_{12}<-\beta \delta\left(v_{12}+v_{22}\right) \Leftrightarrow v_{11}+2 v_{12}+v_{22}-(1-\beta \delta)\left(v_{12}+v_{22}\right)<0$

which is always satisfied, since $v(a, a)$ is concave, $v_{12}+v_{22}>0$ and $\left.\beta \delta \in\right] 0,1[$. Thus, the values of $\hat{a}$ and $\bar{a}$ can easily be compared.

If $v_{2}(\bar{a}, \bar{a})>0$, then $-\beta \delta v_{2}(\bar{a}, \bar{a})<0$ and $\hat{a}>\bar{a}$ (see figure 1 )

If $v_{2}(\bar{a}, \bar{a})<0$, then $-\beta \delta v_{2}(\bar{a}, \bar{a})>0$ and $\hat{a}<\bar{a}$ (see figure 2)

Case 1.2 : Strategic substitutability : $v_{12}<0$

If $v_{12}<0, \beta<0$ and $-\beta \delta v_{2}(a, a)$ is increasing, with a slope $-\beta \delta\left(v_{12}+v_{22}\right)>0$. 
If $v_{2}(\bar{a}, \bar{a})>0$, then $-\beta \delta v_{2}(\bar{a}, \bar{a})>0$ and $\hat{a}<\bar{a}$ (see figure 3 )

If $v_{2}(\bar{a}, \bar{a})<0$, then $-\beta \delta v_{2}(\bar{a}, \bar{a})<0$ and $\hat{a}>\bar{a}$ (see figure 4)

Case 2: We suppose $v_{2}(a, a)$ is decreasing, ie $v_{21}+v_{22}<0$.

Case 2.1: Strategic complementarity : $v_{12}>0$

If $v_{12}>0, \beta>0$ and $-\beta \delta v_{2}(a, a)$ is increasing, with a slope $-\beta \delta\left(v_{12}+v_{22}\right)>0$.

If $v_{2}(\bar{a}, \bar{a})<0$, then $-\beta \delta v_{2}(\bar{a}, \bar{a})>0$ and $\hat{a}<\bar{a}$ (see figure 3 )

If $v_{2}(\bar{a}, \bar{a})>0$, then $-\beta \delta v_{2}(\bar{a}, \bar{a})<0$ and $\hat{a}>\bar{a}$ (see figure 4)

Case 2.2 : Strategic substitutability : $v_{12}<0$

If $v_{12}<0, \beta<0$ and $-\beta \delta v_{2}(a, a)$ is decreasing, with a slope $-\beta \delta\left(v_{12}+v_{22}\right)<0$. The slope of $v_{1}(a, a)$ is larger, in absolute value than the slope of $-\beta \delta v_{2}(a, a)$ since :

$v_{11}+v_{12}<-\beta \delta\left(v_{12}+v_{22}\right) \Leftrightarrow v_{11}+\beta \delta v_{22}-(1+\beta \delta) v_{12}<0$

which is satisfied because the restriction of the lemma implies $\left|v_{11}\right|>\left|\delta v_{22}\right|>\left|\beta \delta v_{22}\right|$ and it is assumed that $\left.v_{11}<0, \quad \beta \delta \in\right]-1,1[$. This implies that :

If $v_{2}(\bar{a}, \bar{a})<0$, then $-\beta \delta v_{2}(\bar{a}, \bar{a})<0$ and $\hat{a}>\bar{a}$ (see figure 1 )

If $v_{2}(\bar{a}, \bar{a})>0$, then $-\beta \delta v_{2}(\bar{a}, \bar{a})>0$ and $\hat{a}<\bar{a}$ (see figure 2 )

QED 


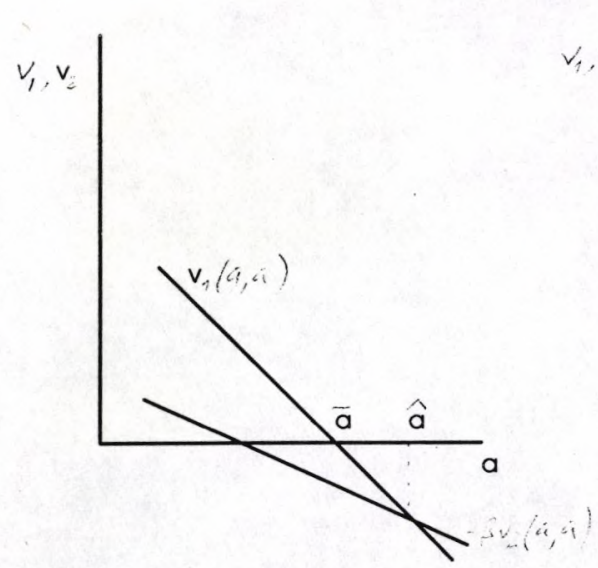

figure 1

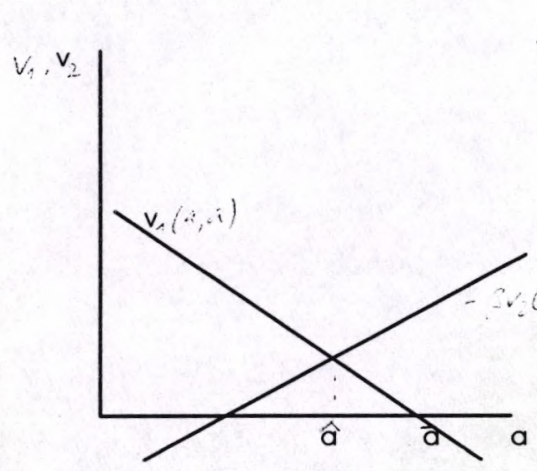

figure 3

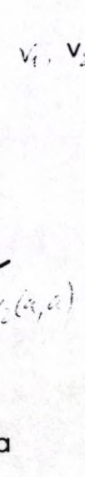

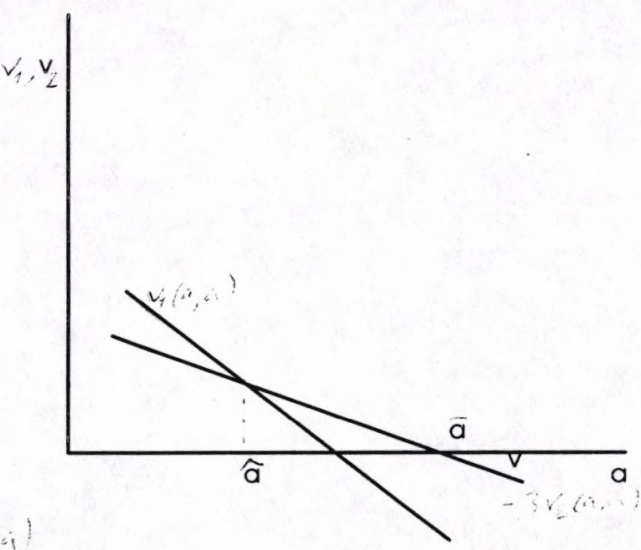

figure 2

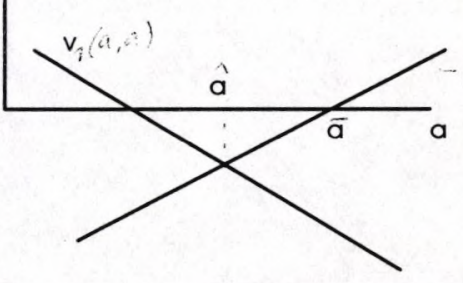

figure 4 


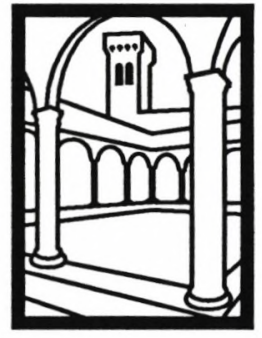

EUI

WORKING PAPERS

EUI Working Papers are published and distributed by the European University Institute, Florence

Copies can be obtained free of charge - depending on the availability of stocks - from:

The Publications Officer

European University Institute Badia Fiesolana

I-50016 San Domenico di Fiesole (FI)

Italy 


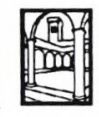

\section{Publications of the European University Institute}

\section{Department of Economics Working Paper Series}

To

Department of Economics WP

European University Institute

Badia Fiesolana

I-50016 San Domenico di Fiesole (FI)

E-mail: publish@datacomm.iue.it

Italy

From Name

Address

(Please print)

$\square$ Please enter/confirm my name on EUI Economics Dept. Mailing List

$\square$ Please send me a complete list of EUI Working Papers

$\square$ Please send me a complete list of EUI book publications

$\square$ Please send me the EUI brochure Academic Year 1995/96

Please send me the following EUI ECO Working Paper(s):

No, Author

Title:

No, Author

Title:

No, Author

Title:

No, Author

Title:

Date 


\section{Working Papers of the Department of Economics Published since 1993}

ECO No. 93/1

Carlo GRILLENZONI

Forecasting Unstable and Non-Stationary Time Series

ECO No. 93/2

Carlo GRILLENZONI

Multilinear Models for Nonlinear Time Series

ECO No. 93/3

Ronald M. HARSTAD/Louis PHLIPS

Futures Market Contracting When You

Don't Know Who the Optimists Are

ECO No. 93/4

Alan KIRMAN/Louis PHLIPS

Empirical Studies of Product Markets

ECO No. 93/5

Grayham E. MIZON

Empirical Analysis of Time Series:

Illustrations with Simulated Data

ECO No. 93/6

Tilman EHRBECK

Optimally Combining Individual

Forecasts From Panel Data

ECO NO. 93/7

Víctor GÓMEZ/Agustín MARAVALL Initializing the Kalman Filter with

Incompletely Specified Initial Conditions

ECO No. 93/8

Frederic PALOMINO

Informed Speculation: Small Markets

Against Large Markets

ECO NO. 93/9

Stephen MARTIN

Beyond Prices Versus Quantities

ECO No. 93/10

José María LABEAGA/Angel LÓPEZ

A Flexible Demand System and VAT

Simulations from Spanish Microdata

ECO No. 93/11

Maozu LU/Grayham E. MIZON

The Encompassing Principle and

Specification Tests
ECO No. 93/12

Louis PHLIPS/Peter MØLLGAARD

Oil Stocks as a Squeeze Preventing

Mechanism: Is Self-Regulation Possible?

ECO No. 93/13

Pieter HASEKAMP

Disinflation Policy and Credibility: The

Role of Conventions

ECO No. 93/14

Louis PHLIPS

Price Leadership and Conscious

Parallelism: A Survey

ECO No. 93/15

Agustín MARAVALL

Short-Term Analysis of Macroeconomic Time Series *

ECO No. 93/16

Philip Hans FRANSES/Niels

HALDRUP

The Effects of Additive Outliers on Tests for Unit Roots and Cointegration

ECO No. 93/17

Fabio CANOVA/Jane MARRINAN

Predicting Excess Returns in Financial

Markets

ECO No. 93/18

Iñigo HERGUERA

Exchange Rate Fluctuations, Market

Structure and the Pass-through

Relationship

ECO No. 93/19

Agustín MARAVALL

Use and Misuse of Unobserved

Components in Economic Forecasting

ECO No. 93/20

Torben HOLVAD/Jens Leth

HOUGAARD

Measuring Technical Input Efficiency for Similar Production Units:

A Survey of the Non-Parametric

Approach 
ECO No. 93/21

Stephen MARTIN/Louis PHLIPS

Product Differentiation, Market Structure and Exchange Rate Passthrough

ECO No 93/22

F. CANOVA/M. FINN/A. R. PAGAN

Evaluating a Real Business Cycle Model

ECO No 93/23

Fabio CANOVA

Statistical Inference in Calibrated Models

ECO No 93/24

Gilles TEYSSIÈRE

Matching Processes in the Labour Market in Marseilles. An Econometric Study

ECO No 93/25

Fabio CANOVA

Sources and Propagation of International

Business Cycles: Common Shocks or

Transmission?

ECO No. 93/26

Marco BECHT/Carlos RAMÍREZ

Financial Capitalism in Pre-World War I

Germany: The Role of the Universal

Banks in the Financing of German

Mining Companies 1906-1912

ECO No. 93/27

Isabelle MARET

Two Parametric Models of Demand,

Structure of Market Demand from

Heterogeneity

ECO No. 93/28

Stephen MARTIN

Vertical Product Differentiation, Intra-

industry Trade, and Infant Industry

Protection

ECO No. 93/29

J. Humberto LOPEZ

Testing for Unit Roots with the k-th

Autocorrelation Coefficient

ECO No. 93/30

Paola VALBONESI

Modelling Interactions Between State and

Private Sector in a "Previously" Centrally

Planned Economy
ECO No. 93/31

Enrique ALBEROLA ILA/J. Humberto

LOPEZ/Vicente ORTS RIOS

An Application of the Kalman Filter to the Spanish Experience in a Target Zone (1989-92)

ECO No. 93/32

Fabio CANOVA/Morten O. RAVN

International Consumption Risk Sharing

ECO No. 93/33

Morten Overgaard RAVN

International Business Cycles: How much can Standard Theory Account for?

ECO No. 93/34

Agustín MARAVALL

Unobserved Components in Economic

Time Series *

ECO No. 93/35

Sheila MARNIE/John

MICKLEWRIGHT

Poverty in Pre-Reform Uzbekistan:

What do Official Data Really Reveal? *

ECO No. 93/36

Torben HOLVAD/Jens Leth

HOUGAARD

Measuring Technical Input Efficiency for

Similar Production Units:

80 Danish Hospitals

ECO No. 93/37

Grayham E. MIZON

A Simple Message for Autocorrelation

Correctors: DON'T

ECO No. 93/38

Barbara BOEHNLEIN

The Impact of Product Differentiation on

Collusive Equilibria and Multimarket

Contact

ECO No. 93/39

H. Peter MØLLGAARD

Bargaining and Efficiency in a

Speculative Forward Market

垱洸 
ECO No. 94/1

Robert WALDMANN

Cooperatives With Privately Optimal Price Indexed Debt Increase Membership When Demand Increases

ECO No. 94/2

Tilman EHRBECK/Robert

WALDMANN

Can Forecasters' Motives Explain

Rejection of the Rational Expectations

Hypothesis?

ECO No. 94/3

Alessandra PELLONI

Public Policy in a Two Sector Model of

Endogenous Growth *

ECO No. 94/4

David F. HENDRY

On the Interactions of Unit Roots and

Exogeneity

ECO No. 94/5

Bernadette GOVAERTS/David F. HENDRY/Jean-François RICHARD

Encompassing in Stationary Linear

Dynamic Models

ECO No. 94/6

Luigi ERMINI/Dongkoo CHANG

Testing the Joint Hypothesis of Rationality and Neutrality under Seasonal Cointegration: The Case of Korea

ECO No. 94/7

Gabriele FIORENTINI/Agustín

MARAVALL

Unobserved Components in ARCH

Models: An Application to Seasonal

Adjustment *

ECO No. 94/8

Niels HALDRUP/Mark SALMON

Polynomially Cointegrated Systems and their Representations: A Synthesis

ECO No. 94/9

Mariusz TAMBORSKI

Currency Option Pricing with Stochastic Interest Rates and Transaction Costs:

A Theoretical Model

ECO No. 94/10

Mariusz TAMBORSKI

Are Standard Deviations Implied in

Currency Option Prices Good Predictors

of Future Exchange Rate Volatility?
ECO No. 94/11

John MICKLEWRIGHT/Gyula NAGY

How Does the Hungarian Unemploy-

ment Insurance System Really Work? *

ECO No. 94/12

Frank CRITCHLEY/Paul

MARRIOTT/Mark SALMON

An Elementary Account of Amari's

Expected Geometry

ECO No. 94/13

Domenico Junior MARCHETTI

Procyclical Productivity, Externalities and Labor Hoarding: A Reexamination of Evidence from U.S. Manufacturing

ECO No. 94/14

Giovanni NERO

A Structural Model of Intra-European

Airline Competition

ECO No. 94/15

Stephen MARTIN

Oligopoly Limit Pricing: Strategic

Substitutes, Strategic Complements

ECO No. 94/16

Ed HOPKINS

Learning and Evolution in a

Heterogeneous Population

ECO No. 94/17

Berthold HERRENDORF

Seigniorage, Optimal Taxation, and Time

Consistency: A Review

ECO No. 94/18

Frederic PALOMINO

Noise Trading in Small Markets *

ECO No. 94/19

Alexander SCHRADER

Vertical Foreclosure, Tax Spinning and

Oil Taxation in Oligopoly

ECO No. 94/20

Andrzej BANIAK/Louis PHLIPS

La Pléiade and Exchange Rate Pass-

Through

ECO No. 94/21

Mark SALMON

Bounded Rationality and Learning;

Procedural Learning 
ECO No. 94/22

Isabelle MARET

Heterogeneity and Dynamics of

Temporary Equilibria: Short-Run Versus

Long-Run Stability

ECO No. 94/23

Nikolaos GEORGANTZIS

Short-Run and Long-Run Cournot

Equilibria in Multiproduct Industries

ECO No. 94/24

Alexander SCHRADER

Vertical Mergers and Market Foreclosure:

Comment

ECO No. 94/25

Jeroen HINLOOPEN

Subsidising Cooperative and Non-

Cooperative R\&D in Duopoly with

Spillovers

ECO No. 94/26

Debora DI GIOACCHINO

The Evolution of Cooperation:

Robustness to Mistakes and Mutation

ECO No. 94/27

Kristina KOSTIAL

The Role of the Signal-Noise Ratio in

Cointegrated Systems

ECO No. 94/28

Agustín MARAVALL/Víctor GÓMEZ

Program SEATS "Signal Extraction in

ARIMA Time Series" - Instructions for the User

ECO No. 94/29

Luigi ERMINI

A Discrete-Time Consumption-CAP

Model under Durability of Goods, Habit

Formation and Temporal Aggregation

ECO No. 94/30

Debora DI GIOACCHINO

Learning to Drink Beer by Mistake

ECO No. 94/31

Víctor GÓMEZ/Agustín MARAVALL

Program TRAMO "Time Series

Regression with ARIMA Noise, Missing

Observations, and Outliers" -

Instructions for the User
ECO No. 94/32

Ákos VALENTINYI

How Financial Development and

Inflation may Affect Growth

ECO No. 94/33

Stephen MARTIN

European Community Food Processing

Industries

ECO No. 94/34

Agustín MARAVALL/Christophe

PLANAS

Estimation Error and the Specification of

Unobserved Component Models

ECO No. 94/35

Robbin HERRING

The "Divergent Beliefs" Hypothesis and the "Contract Zone" in Final Offer

Arbitration

ECO No. 94/36

Robbin HERRING

Hiring Quality Labour

ECO No. 94/37

Angel J. UBIDE

Is there Consumption Risk Sharing in the EEC?

ECO No. 94/38

Berthold HERRENDORF

Credible Purchases of Credibility

Through Exchange Rate Pegging:

An Optimal Taxation Framework

ECO No. 94/39

Enrique ALBEROLA ILA

How Long Can a Honeymoon Last?

Institutional and Fundamental Beliefs in the Collapse of a Target Zone

ECO No. 94/40

Robert WALDMANN

Inequality, Economic Growth and the

Debt Crisis

ECO No. 94/41

John MICKLEWRIGHT/

Gyula NAGY

Flows to and from Insured

Unemployment in Hungary 
ECO No. 94/42

Barbara BOEHNLEIN

The Soda-ash Market in Europe:

Collusive and Competitive Equilibria

With and Without Foreign Entry

ECO No. 94/43

Hans-Theo NORMANN

Stackelberg Warfare as an Equilibrium

Choice in a Game with Reputation Effects

ECO No. 94/44

Giorgio CALZOLARI/Gabriele

FIORENTINI

Conditional Heteroskedasticity in

Nonlinear Simultaneous Equations

ECO No. 94/45

Frank CRITCHLEY/Paul MARRIOTT/

Mark SALMON

On the Differential Geometry of the Wald

Test with Nonlinear Restrictions

ECO No. 94/46

Renzo G. AVESANI/Giampiero M.

GALLO/Mark SALMON

On the Evolution of Credibility and

Flexible Exchange Rate Target Zones

\section{粠粠}

ECO No. 95/1

Paul PEZANIS-CHRISTOU

Experimental Results in Asymmetric

Auctions - The 'Low-Ball' Effect

ECO No. 95/2

Jeroen HINLOOPEN/Rien

WAGENVOORT

Robust Estimation: An Example

ECO No. $95 / 3$

Giampiero M. GALLO/Barbara PACINI

Risk-related Asymmetries in Foreign

Exchange Markets

ECO No. 95/4

Santanu ROY/Rien WAGENVOORT

Risk Preference and Indirect Utility in

Portfolio Choice Problems

ECO No. 95/5

Giovanni NERO

Third Package and Noncooperative

Collusion in the European Airline

Industry
ECO No. 95/6

Renzo G. AVESANI/Giampiero M.

GALLO/Mark SALMON

On the Nature of Commitment in Flexible

Target Zones and the Measurement of

Credibility: The 1993 ERM Crisis

ECO No. 95/7

John MICKLEWRIGHT/Gyula NAGY

Unemployment Insurance and Incentives in Hungary

ECO No. 95/8

Kristina KOSTIAL

The Fully Modified OLS Estimator as a

System Estimator: A Monte-Carlo

Analysis

ECO No. 95/9

Günther REHME

Redistribution, Wealth Tax Competition and Capital Flight in Growing

Economies

ECO No. 95/10

Grayham E. MIZON

Progressive Modelling of

Macroeconomic Time Series: The LSE

Methodology

ECO No. 95/11

Pierre CAHUC/Hubert KEMPF

Alternative Time Patterns of Decisions and Dynamic Strategic Interactions 
